\title{
IMPACT OF BUILDING INFORMATION MODELING ON JUST-IN-TIME MATERIAL
} DELIVERY

\author{
*I.A. Ocheoha, O. Moselhi \\ Department of Building, Civil and Environmental Engineering, Concordia University \\ 1455 De Maisonneuve Blvd. West \\ Montreal, QC H3G 1M8, Canada \\ (*Corresponding author: alex_ocheoha@hotmail.com)
}




\title{
IMPACT OF BUILDING INFORMATION MODELING ON JUST-IN-TIME MATERIAL DELIVERY
}

\begin{abstract}
The purpose of this research is to evaluate the impact of Building Information Modeling (BIM) on Just-In-Time (JIT) material delivery, with a focus on how the use of BIM can help improve efficient implementation of JIT and reduce the cost of material management. Previous research and a number of case studies have addressed the positive impact of BIM on construction at large but none focused on JIT in construction. This paper presents a methodology for selecting reliable material vendors. It also utilises the integration of BIM and scheduling software to generate quantities of material and its required delivery time to improve the flow process and improve its reliability to minimise related delays and productivity losses arising from idle and non-productive time of equipment and labour on jobsites. 4D visualization is utilized to support coordination and timing of JIT material deliveries in an effort to minimize congestion on job sites. Case studies on JIT material deliveries are presented and the impact of BIM implementation on reducing the cost of material management is evaluated. The joint effect of BIM and JIT on quality control, elimination of waste, reduction of inventory buffers, and on relationships with material vendors are evaluated by analysing and comparing data from case studies. The paper also presents a methodology based on multi-attribute decision criteria for modelling the selection criteria for material vendors. The model can assist in ranking vendors not only based on cost and quality but also on their reliability in delivering material on time.
\end{abstract}

\section{KEYWORDS}

Building Information Modeling (BIM), Just-In-Time (JIT), Material Management, Vendor selection

\section{INTRODUCTION}

Efficient material management is crucial to project success. Materials stock outs, improper storage of materials, double handling, inefficient methods, and out-of-sequence deliveries, have been observed as some of the most frequently occurring material management deficiencies on jobsites which disrupts workflow and reduces productivity (Thomas, Riley \& Messner, 2005). Just-in-time material delivery involves delivering the right quantities of materials just in time for use or installation. Perishable commodities such as ready mixed concrete must be delivered in the right quantities just in time for use. Up to $1.6 \%$ of total volume of ready mixed concrete was estimated by plant operators as wastes due to incorrect timing of deliveries and inaccuracies in ordered quantities (Tommelein \& Li, 1999). JIT material deliveries are also inevitable in confined job sites most especially in busy downtown areas with restricted lay-down areas. The advantages of JIT in construction include reduced inventories, improved quality and increased productivity (Ansari \& Modarress 1990; Ballard and Howell, 1995; Pheng \& Chuan, 2001; Pheng \& Tan, 1998).

BIM has a positive impact on JIT material deliveries which enhances the benefits of JIT implementation. Visualization using BIM helps clients and other project stakeholders to understand complex projects. Reduced uncertainty and improved predictability from the visualization of the construction project over time helps to ensure an uninterrupted workflow and increase productivity. BIM generates accurate material quantities and helps to ensure a reliable delivery schedule which is important during JIT implementation. 
Material vendors play a crucial role in the successful implementation of JIT. Late delivery of materials can lead to delays which may negatively impact the overall project schedule. With the use of BIM on construction projects the technological capabilities of vendors become increasingly important. However, in selecting the best material vendor factors beyond cost and quality still need to be considered. This paper presents a simple vendor selection decision support methodology based on multi-attribute decision criteria for modelling the selection criteria for material vendors. The model will rank vendors not only based on cost and quality but also on their technological capabilities and reliability in delivering materials on time.

\section{BACKGROUND ON TOOLS UTILIZED}

\section{Building information modeling (BIM)}

BIM is a modeling technology and associated set of processed to produce, communicate and analyze building models which are composed of components represented by digital objects that carry data and parametric rules (Teicholz, Sacks \& Liston, 2011). Azhar, Hein, and Sketo (2008) determined the cost and time savings realized by using building information modeling using data from Hilton Aquarium project in Atlanta and several other construction projects. Suermann (2009) through a survey showed that quality, cost and on time completion were the top three construction Key Performance Indicators (KPIs) perceived as most benefitted by BIM. The advantages of 3D-BIM and 4D-BIM which were documented include: early multidisciplinary collaboration, accurate generation of 2D drawings from BIM, clash detection, reduced field coordination problems, increased productivity, fewer requests for information, and fewer change orders.

\section{Just-In-Time (JIT)}

The Just-In-Time (JIT) philosophies aims to eliminate inventory, eliminate waste, smooth the flow of materials as well as improve productivity. Just in Time material delivery aims to deliver the right amount of material just in time for use or installation.

Table 1: The fundamental principles of JIT

\begin{tabular}{ll}
\hline Elimination of waste & $\begin{array}{l}\text { Elimination of waste from overproduction, wastes from waiting } \\
\text { time, Transportation waste, processing waste, inventory waste, } \\
\text { waste of motion and waste from product defects (Ohno, 1988). }\end{array}$ \\
\hline $\begin{array}{l}\text { The "Kanban" or "pull } \\
\text { system" }\end{array}$ & $\begin{array}{l}\text { The Kanban system pulls materials as needed on a Just-In-Time } \\
\text { basis. (Arbulu, Ballard \& Harper, 2003) }\end{array}$ \\
\hline Uninterrupted work flow & $\begin{array}{l}\text { Simplifying the workflow, automation, reduction of process set- } \\
\text { up times, and machine/equipment preventive maintenance } \\
\text { programmes. }\end{array}$ \\
\hline Total quality Control & $\begin{array}{l}\text { Total quality control concept aims to eliminate work defects and } \\
\text { receive materials without defects. }\end{array}$ \\
\hline Concept & $\begin{array}{l}\text { Top management commitment to training and preventive } \\
\text { maintenance programmes as well employee involvement in } \\
\text { identifying ways to improve operations and working with greater } \\
\text { clexibility. }\end{array}$ \\
\hline involvementment & $\begin{array}{l}\text { A long term relationship with a single or fewer reliable suppliers } \\
\text { who deliver high quality materials in smaller lot sizes more } \\
\text { frequently just in time for use. Responding to the needs and } \\
\text { demands of clients who provide the money. }\end{array}$ \\
\hline Supplier and client relations & $\begin{array}{l}\text { Top management and employees both seek ways to continuously } \\
\text { improving existing processes by reducing or eliminating non- } \\
\text { value adding activities. }\end{array}$ \\
\hline $\begin{array}{l}\text { Continuous improvements } \\
\text { ('Kaizen' in Japanese) }\end{array}$ &
\end{tabular}




\section{Benefits of JIT}

The implementation of JIT does not require large capital expenditure on plant and equipment but rather investment in training of employees and reorganization of work processes. JIT has both quantifiable and unquantifiable benefits. In Denmark, Bertelsen (1995) reported a 7 - 10\% increases in productivity in the construction of a social housing project that experimented with the use of the JIT philosophy in building logistics. The benefits of JIT are: reduced inventories, improved quality, increased flexibility, increased productivity and reduced space requirements.

\section{Impact of BIM on Just In Time Material Deliveries}

BIM has a positive impact of just in time material deliveries which are both quantifiable and unquantifiable. The quantifiable benefits are the reduction of material inventory, improvements in quality and waste reduction. The unquantifiable benefits include visualization and productivity improvements, as well as improved communication and collaboration, and field co-ordination problems during deliveries. BIM has a positive impact on the fundamental Principles of JIT. Quantity take-offs generated from BIM models helps in the elimination of waste while 4D-BIM can be used for quality control, continuous improvement and helps to ensure uninterrupted workflow which improves productivity. Visualization gives clients a better understanding of the project. BIM generated prefabricated components and more accurate material delivery schedules improves relationships with suppliers. JIT can be aided by RFID as an electronic KANBAN in triggering a pull (Brintrup, Ranasinghe, \& McFarlane, 2010), when the material has been installed in the right place and is updated in the model.

\section{$\underline{\text { Inventory Reduction }}$}

Reduction of inventory buffers would reduce waste arising from double handling of materials or inventory holding costs such as storage costs, space, risk of theft or damage, obsolescence, insurance, cash tied up in inventory, finance costs, etc. Inventories buffers are held to meet fluctuations in demand to ensure that there are no stock outs which leads to lost labor time, idle machinery, productivity loss and project delays. 4D-BIMcan be used to generate a reliable delivery schedule.

Quantity take-offs generated from 2D drawings use some assumptions to arrive at material quantities which can be overestimated and may contain errors or omissions. Excess unused materials may end up as waste or scrap. Inaccurate quantity take-offs are one of the factors that lead to time and cost overruns in high rise projects in Indonesia (Kaming, Olomolaiye, Holt \& Harris, 1997)

BIM can extract the areas and volumes of objects and provide a more accurate and automated quantification of the building model. It takes less time to generated more reliable quantity take-offs and estimates from BIM models. BIM can respond to changes in design and can automatically generate quantity take-offs at any time during design or construction. More accurate quantities of materials can be delivered when using Just-In-Material deliveries. Villafana (2011) using a case study compared the quantity take-off estimates from models which were developed after construction to the original estimate by the contractor and the actual material procured which showed a $22 \%$ decrease from the original estimate.

\section{Improved Quality}

JIT aims to improve quality by eliminating material defects. Prefabrication technology brings improved quality with better quality controls, reduction of wastes, less-labour intensive operations and faster construction of buildings (Pheng \& Chan, 1996). Prefabricated components are required to be of good quality and fit accurately. Pheng \& Chuan, (2001) listed rejected batch due to poor quality as one of the causes of work delays involving precast components. Waste results from rejected components which do not fit accurately and from time spent on rectification works to make components fit in place. 
BIM can generate data of component details for prefabrication software for higher quality components to be fabricated using Computer Numerical Control (CNC) machines. RFID combined with BIM can be used for quality control. During the construction of the 84,000-seat stadium in New Jersey's Meadowlands, RFID was used to track about 3200 pre-cast structural elements, from casting to shipping, delivery and placement to ensure that they were produced and placed in the right sequence (Sawyer, 2008).

\section{Visualisation}

Visualization of the project and jobsite and can enhance communication between project managers and constructors Owners will have a better understanding of the project at the design stage and make an early input which reduces the possibility of change orders. Visualisation can be used to confirm the location of components relative to other components or objects to resolve any conflicts or interference early in design process.

A 4D-BIM model combines a 3D model with time. Objects in the model are linked to a CPM schedule to show the visualization of the project at each instant in time. This helps all stakeholders to understand the construction process, the project at any stage and how the completed project will look. Visualisation of workspaces helps to resolve any clashes between sub-trades or site congestion which can disrupt workflow prior to construction. Continuous improvements could be planned by visualizing the construction process and having a better understanding how it will work. 4D-BIM Models can include access routes and temporary equipment such as tower cranes which can be used to plan material deliveries and coordinate material handling equipment such as tower cranes and ensure their availability. Uninterrupted material flow is critical during deliveries most especially when there are other scheduled deliveries and there is a limited laydown area. Savings could be realised through improved productivity, fewer field coordination problems and clash detection.

Materials with RFID tags linked to objects in a BIM model can capture data and update the model. The visibility of the real-time project status can be used to monitor progress and make possible improvements. Staub-French and Khanzode (2007) through case studies identified the benefits of 4D modelling in assisting the coordination of schedules of different subcontractors, coordinating equipment placement, identifying constructability issues, elimination of field interferences and decreasing project duration.

\section{PROPOSED METHOD}

The selection of reliable material vendor is a critical decision which is faced by many owners. The objective in selecting a vendor for JIT material deliveries is to select the best material vendor, not the vendor that has the lowest price. The vendor selection problem is a multi-criteria decision making problem which considers several qualitative or quantitative criteria and are in conflict with one another. Several authors have reviewed different vendor selection methods used in Just-In-Time environments, (Aksoy \& Öztürk, 2011; Weber, Current, \& Benton, 1991). The proposed method is based on a simple and comprehensive decision support methodology, which avoids time consuming analysis and accounts for risk (Moselhi, 1994). It is based on multi-attribute utility theory "MAUT" (Ang \& Tang, 1984).

\section{Vendor Selection Criteria}

The owners need to evaluate several criteria to select reliable material vendors. Quality is a very important criterion when implementing JIT. Delays can be caused by material rejects due to defects or poor quality. JIT does not accept product defects therefore product quality will be extremely important. Previous studies on supplier evaluation criteria stated several criteria which can be used in the selection of reliable material vendors. Freeland (1991) ranked quality as the most important criterion from the findings of a survey of just-in-time purchasing practices in 60 different industries in the USA. Weber et al (1991) also mentioned quality as most important in the implementation of JIT after a review of 74 research articles on criteria and methods used for vendor selection. Several other authors also ranked quality as the most 
important criterion (Ansari \& Modarress, 1990; Ho, Xu, \& Dey, 2010; Kannan \& Tan, 2002). Table 2 below lists the 5 most important criteria identified by different authors.

Table 2 - JIT criteria for vendor selection

\begin{tabular}{ccccc}
\hline RANK & $\begin{array}{c}\text { ANSARI \& } \\
\text { MODARRESS (1990) }\end{array}$ & WEBER et al (1991) & $\begin{array}{c}\text { KANNAN } \\
\text { \&TAN (2002) }\end{array}$ & HO et al (2010) \\
\hline 1. & product quality & Quality & Quality level & Quality \\
\hline 2. & supplier relationship & Delivery & Service level & Delivery \\
\hline 3. & delivery performance & Net price & On-time delivery & Price/cost \\
\hline 4. & price & Geographical location & $\begin{array}{c}\text { Quick response } \\
\text { time }\end{array}$ & $\begin{array}{c}\text { Manufacturing } \\
\text { capability }\end{array}$ \\
\hline 5. & & Production facilities \& & Flexibility & Service \\
\hline
\end{tabular}

With the implementation of Building Information Modeling several other criteria such information technology, GPS and RFID technologies need to be considered. These technologies help facilitate the Just-In-Time delivery of material. Electronic Data Interchange(EDI) can be used to remind material vendors timing, exact quantities, types and any rescheduling of delivery to site if used for communication with them (Akintoye, 1995). A combination of Global Positioning System (GPS) and Geographic Information System (GIS) can be used to efficiently track locations of materials (Lu, Chen, Shen, Lam \& Liu, 2007). Jaselskis and El-Misalami (2003) showed that RFID can help save time in the material receiving process and in recording information into the material tracking system.

For this research the top 5 criteria considered most important for JIT material delivery will be further considered. These criteria which were determined from literature are Quality, Delivery, Net price, Geographical location/proximity and Technology.

\section{Step 1: Establish the decision criteria}

The criteria and their relative weights are established preferably in a hierarchical order. This is done using pairwise comparisons and assigning 1 for a criteria equal to or greater than the other which is assigned 0 as shown in table 3 below.

Table 3: Selection Criteria and their relative weights

\begin{tabular}{llllllll}
\hline & Quality & Delivery & Price & Proximity & Technology & $\begin{array}{c}\text { Weight } \\
\text { Value }\end{array}$ & $\begin{array}{c}\text { Normalized } \\
\text { weight value }\end{array}$ \\
\hline Quality & 0 & 1 & 1 & 1 & 1 & 4 & 0.4 \\
\hline Delivery & 0 & 0 & 1 & 1 & 1 & 3 & 0.3 \\
\hline Price & 0 & 0 & 0 & 1 & 1 & 0 & 0.2 \\
\hline Proximity & 0 & 0 & 0 & 0 & 0 & 1 & 0.1 \\
\hline Technology & 0 & 0 & 0 & 1 & 0 & 10 & 1.0 \\
\hline
\end{tabular}

Step 2: Quantify the risk associated with each criteria and the expected value

The mean and standard deviation are calculated for the marginal distribution associated with each criteria.

Step 3: Represent subjective criteria 
This is done using a 10 point scale where 10 is assigned the most desirable value and 0 the least desirable value.

\section{Step 4: Develop the decision maker's utility function}

The utility function $\mathrm{U}(\mathrm{x})$ is developed for each attribute by using the value of 1.0 as equal to the most desirable and $\mathrm{U}(\mathrm{x})$ as 0.0 for the least satisfaction of the decision maker.

Step 5: Calculate the expected utility e (U)

For a single objective Equation [1] becomes:

$$
E[U]=[U] .[V] .[W]
$$

Where [W] is the weight vector established in step 1, [U] and [V] are the utility and objective matrices and are expressed as follows:

$$
[U]=\left[\begin{array}{ccc}
\left(1 / \mu_{1}\right) U\left(\mu_{1}\right) & (1 / 2 !) U_{1}^{\prime \prime}\left(\mu_{1}\right) & (1 / 3 !) U_{1}^{\prime \prime \prime}\left(\mu_{1}\right) \ldots . \\
\left(1 / \mu_{1}\right) U\left(\mu_{1}\right) & (1 / 2 !) U_{1}^{\prime \prime}\left(\mu_{1}\right) & (1 / 3 !) U_{1}^{\prime \prime \prime}\left(\mu_{1}\right) \ldots \\
\ldots & \ldots \ldots . & \ldots \ldots \ldots \\
\left(1 / \mu_{1}\right) U\left(\mu_{1}\right) & (1 / 2 !) U_{1}^{\prime \prime}\left(\mu_{1}\right) & (1 / 3 !) U_{1}^{\prime \prime \prime}\left(\mu_{1}\right) \ldots
\end{array}\right]
$$

in which

$$
\begin{gathered}
U^{\prime \prime}=\frac{d^{2} U}{d x^{2}}, \text { and } U^{\prime \prime \prime}=\frac{d^{3} U}{d x^{3}} \\
{[V]=\left[\begin{array}{lllll}
\mu_{1} & \mu_{2} & \mu_{3} & \ldots & \mu_{n} \\
\sigma_{1}^{2} & \sigma_{2}^{2} & \sigma_{3}^{2} & \ldots & \sigma_{n}^{2} \\
k_{1} & k_{2} & k_{3} & \ldots & k_{n} \\
m_{1} & m_{2} & m_{3} & \ldots & m_{n}
\end{array}\right]} \\
\end{gathered}
$$

For a single objective Equation [1] becomes:

$$
E[U]=U(\mu)+0.5 \sigma^{2} U^{\prime \prime}(\mu)
$$

In cases where uncertainty does not need to be considered, Equation [1] can still be used but the utility matrix will be a column matrix ( populated by elements of the first column) and the objective matrix will be a row matrix(populated by elements of the first row ). The mean $(\mu)$ for each attribute will be used with its standard deviation $(\sigma)$ and higher order statistical moments equal to zero.

\section{CONCLUSIONS}

The research evaluated the impact of Building Information Modeling (BIM) on Just-In-Time (JIT) material delivery and focused on how the use of BIM can help improve the implementation of JIT and 
reduce the cost of material management. BIM has a positive impact on the implementation of JIT delivery of material in construction. BIM helps to identify constructability issues, reduce field coordination problem, resolve potential clashes between sub-trades, avoid site congestions plan material deliveries, coordinate material handling equipment and generate more accurate material quantities and delivery schedules. Uninterrupted workflow and continuous improvements leads to saving from improved productivity, less holding costs of inventory, and elimination of waste due to product defect.

Recent advancements in spatial and remote sensing technologies are expected improve supply chain management and the integrated use GPS and RFID technologies linked to BIM models will ensure efficient implementation of JIT. And the use of such technologies by material suppliers should, therefore, be included in the selection criteria of these suppliers. BIM implementation helps to reduce costs and to improve quality. Considering the impact of BIM on JIT more investigation is needed to quantify the overall effects of implementing BIM in a JIT environment. There is also a need to further investigate how the technological capabilities of material vendors/suppliers affect the selection decision when BIM is being implemented in a JIT environment. Material vendors/ suppliers should be selected based on their technological capabilities and with long term relationships may be made to acquire new technology. However, only large construction firms are likely to influence material vendors. This happened in the retail industry where Walmart mandated its top suppliers to comply with its RFID/electronic product code program (Kinsella, 2003). Small firms may lack the resources to acquire new technology.

\section{REFERENCES}

Akintoye, A. (1995). Just-in-time application and implementation for building material management. Construction Management and Economics, 13(2), 105-113.I

Aksoy, A., \& Öztürk, N. (2011). Supplier selection and performance evaluation in just-in-time production environments. Expert Systems with Applications, 38(5), 6351-6359.

Ang, A. H., \& Tang, W. H. (1984). Probability Concepts in Engineering Planning and Design, vol. II John Wiley \& Sons. Inc, New York.

Ansari, A., Modarress, B., \& Ansari, A. (1990). Just-in-time purchasing. Free Press

Arbulu, R., Ballard, G., \& Harper, N. (2003). Kanban in construction. Proceedings of IGLC-11, Virginia Tech, Blacksburgh, Virginia, USA, 16-17.

Azhar, S., Hein, M., \& Sketo, B. (2008, April). Building information modeling (BIM): Benefits, risks and challenges. In Proceedings of the 44th ASC Annual Conference (pp. 2-5).

Ballard, G., \& Howell, G. (1995). Toward construction JIT. Lean construction, 291-300.

Bertelsen, S. (1995). Building logistics: A means for improvement of productivity in the building sector. Nelleman, Nielsen \& Rauschenberger A/S Consulting Engineers and Planners, Copenhagen, Denmark.

Brintrup, A., Ranasinghe, D., \& McFarlane, D. (2010). RFID opportunity analysis for leaner manufacturing. International Journal of Production Research, 48(9), 2745.

Freeland, J. R. (1991). A survey of just-in-time purchasing practices in the United States. Production and Inventory Management Journal, 32(2), 43-49.

Ho, W., Xu, X., \& Dey, P. K. (2010). Multi-criteria decision making approaches for supplier evaluation and selection: A literature review. European Journal of Operational Research, 202(1), 16-24. 
Jaselskis, E. J., \& El-Misalami, T. (2003). Implementing radio frequency identification in the construction process. Journal of Construction Engineering and Management, 129(6), 680-688.

Kaming, P. F., Olomolaiye, P. O., Holt, G. D., \& Harris, F. C. (1997). Factors influencing construction time and cost overruns on high-rise projects in Indonesia. Construction Management \& Economics, 15(1), 83-94.

Kannan, V. R., \& Tan, K. C. (2002). Supplier selection and assessment: Their impact on business performance. Journal of Supply Chain Management, 38(4), 11-21.

Kinsella, B. (2003). The Wal-mart factor. Industrial Engineer, 35(11), 32-36.

Lu, M., Chen, W., Shen, X., Lam, H. C., \& Liu, J. (2007). Positioning and tracking construction vehicles in highly dense urban areas and building construction sites. Automation in Construction, 16(5), 647656.

Moselhi, O., (1994). Decision support for project execution. In proceedings of the CSCE Annual Conference, Winnipeg (pp. 489-496).

Ohno, T. (1988). Toyota production system: beyond large-scale production. Productivity press.

Pheng, L. S., \& Chan, R. Y. M. (1996). The application of just-in-time principles to process layout for precast concrete production. Singapore Management Review, 18(2), 23-23.

Pheng, L. S., \& Chuan, C. J. (2001). Just-in-time management of precast concrete components. Journal of Construction Engineering and Management, 127(6), 494-501.

Pheng, L. S., \& Tan, S.,K.L. (1998). How "just-in-time" wastages can be quantified: Case study of a private condominium project. Construction Management and Economics, 16(6), 621-635.

Sawyer, T. (2008). Modeling supply chains. ENR, 260(14), 24.

Staub-French, S., \& Khanzode, A. (2007). 3D and 4D modeling for design and construction coordination: issues and lessons learned. ITcon, 12, 381-407.

Suermann, P. C. (2009). Evaluating the impact of building information modeling (BIM) on construction (Doctoral dissertation, University of Florida).

Teicholz, P., Sacks, R., \& Liston, K. (2011). BIM Handbook: A Guide to Building Information Modeling for Owners, Managers, Designers, Engineers, and Contractors. Wiley.

Thomas, H. R., Riley, D. R., \& Messner, J. I. (2005). Fundamental principles of site material management. Journal of construction engineering and management, 131(7), 808-815.

Tommelein, I. D., \& Li, A. (1999, July). Just-in-time concrete delivery: mapping alternatives for vertical supply chain integration. In Proceedings of the 7th Annual Conference of the International Group for Lean Construction IGL-7, University of California, Berkeley, California (pp. 97-108).

Villafana, A. (2011). Evaluation of building information modeling applications for small construction companies. The University of Texas at Arlington).

Weber, C. A., Current, J. R., \& Benton, W. C. (1991). Vendor selection criteria and methods. European journal of operational research, 50(1), 2-18. 